\title{
Amperometric Glucose Biosensor Based on Entrapment of Glucose Oxidase in a Poly(3,4-ethylenedioxythiophene) Film
}

\author{
Po-Chin Nien, ${ }^{\mathrm{a}}$ Tsai-Shih Tung, ${ }^{\mathrm{a}}$ Kuo-Chuan $\mathrm{Ho}^{\mathrm{a}, \mathrm{b} *}$ \\ a Department of Chemical Engineering, National Taiwan University, Taipei 10617, Taiwan \\ b Institute of Polymer Science and Engineering, National Taiwan University, Taipei 10617, Taiwan \\ *e-mail: kcho@ntu.edu.tw
}

Received: April 17, 2006

Accepted: April 20, 2006

\begin{abstract}
In this study, conducting polymer, poly(3,4-ethylenedioxythiophene) (PEDOT), is used as a matrix for the entrapment of glucose oxidase (GOD) and served as the working electrode for sensing glucose. The monomer, EDOT, is electropolymerized onto the platinum electrode by the cyclic voltammetric $(\mathrm{CV})$ technique, scanned between 0.2 and $1.2 \mathrm{~V}$ (vs. $\mathrm{Ag} / \mathrm{AgCl} /$ saturated $\mathrm{KCl}$ ) in a phosphate buffer solution (PBS) containing GOD, which is entrapped into the PEDOT film simultaneously. The biosensor senses the reoxidative current of the mediator, ferricinium ions, with a constant applied potential of $0.35 \mathrm{~V}$ in the sensing system containing a phosphate buffer solution, ferricinium ions, and glucose. The indirect electrochemical method can efficiently reduce the sensing potential of the glucose. The sensing results show that the linear range of the calibration curve for the glucose concentration lies between 0.1 and $10.0 \mathrm{mM}$, which is a suitable level in the human body. Besides, the limit of detection and sensing sensitivity on glucose for the biosensor are $0.13 \mathrm{mM}$ and $12.42 \mathrm{~mA} \mathrm{~cm}^{-2} \mathrm{M}^{-1}$, respectively. The response time of the biosensor, which is defined as the reaction current reaching $95 \%$ of the steady-state current, is about $4-10 \mathrm{~s}$. In the aspects of interferences on ascorbic acid (AA) and uric acid (UA), the sensing currents increased about $9.7 \%$ and $39.1 \%$, respectively, when compared to the sensing current of glucose. Moreover, the biosensor shows a good stability in which the sensing current of the electrode retains $80 \%$ of its original one over a period of 18 days.
\end{abstract}

Keywords: Biosensor, Ferrocene, Glucose, Glucose oxidase, Poly(3,4-ethylenedioxythiophene)

DOI: 10.1002/elan.200603552

\section{Introduction}

The determination of the glucose concentration is important in several aspects for food, microorganism or medicine, especially for diabetes. The normal concentrations range of blood glucose in human body varies from 4 to $8 \mathrm{mM}$, and the concentration may be up to $10 \mathrm{mM}$ for diabetes. Consequently, to develop a stable glucose biosensor is an interesting and crucial research topic for medicine and biochemistry. Clark and Lyons firstly reported a glucose biosensor by encapsulating glucose oxidase within polyethylene on the metal electrodes [1]. According to the prototype of the enzyme electrode, the company of Yellow Spring Instruments in America manufactured the first commercial glucose biosensor, which operated based on the change of the oxygen concentration inside the solution in 1972.

In order to obtain a long operational life of the biomolecules, or enzyme, in an analytic device, the technique of the enzyme-immobilization onto the transducer is a key process to develop a good biosensor. Generally speaking, the reported methods for enzyme-immobilization include adsorption, covalent attachment, cross-linking and entrapment [2]. As for the adsorption method, it utilizes the hydrophilic or hydrophobic properties of the material, such as ion exchange resin [3] and nylon [4] to construct the enzyme electrode. The method of covalent attachment uses the functional group in the biomolecules, such as $-\mathrm{NH}_{2}$, $-\mathrm{COOH}$, and $-\mathrm{SH}$, for binding with transducer chemically [5]. On the other hand, cross-linking method uses crosslinking agent, such as glutaral, to combine the biomolecules and polymer. However, the adsorption method can not grasp enzyme easily because of the weak attraction to electrode; besides, the covalent attachment and cross-linking methods may be difficult to retain the enzyme activity. In contrast, the approach of enzyme-immobilization, or enzyme entrapment, is attractive in recent years due to stronger adhesion between enzyme and matrix. For example, the material, such as carbon gel [6] and polyvinyl chloride [7], was used to immobilize the enzyme onto the electrode. Besides, the method, which entraps biomolecules onto the electrode surface electrochemically, have also been extensively investigated recently [8].

Foulds et al. firstly reported that an enzyme can be entrapped into the conducting polymers by using electrochemical polymerization [9]. Electropolymerized conducting polymers and entrapping the enzyme onto a platinum electrode simultaneously is a simple, attractive and appreciable way to construct biosensors [10]. In addition, the thickness of the polymerized film can be easily controlled by 
choosing the deposition time in a one-step procedure. The conducting polymers, which were deposited electrochemically to immobilize an enzyme, include polyaniline [11-12], polythiophene [13] and polypyrrole (PPy) [14-16]. In this work, conducting polymer, PEDOT, is served as the matrix to fabricate an amperometric glucose biosensor. In a previous work, Yamato et al. [17] pointed out that when the conducting polymers, PPy and PEDOT, which were deposited on platinum electrode with poly(styrene sulfonate) (PSS) by means of cyclic voltammetry (CV) were applied at $400 \mathrm{mV}$ (vs. $\mathrm{Ag} / \mathrm{AgCl} / 3 \mathrm{M} \mathrm{KCl}$ ) in phosphate buffer ( $\mathrm{pH} 7.0$ ) in a period of 16 hours, the electroactivity of PEDOT and PPy retained $87 \%$ and $5 \%$ of their original activity, respectively. Even applied potential after 80 hours, PEDOT still retained $76 \%$ of its original electroactivity and this shows that the good electrochemical stability of PEDOT in phosphate buffer ensures its possible applications in biosensors. The good electrochemical stability of the PEDOTwas reported in other studies [18-20]. In the aspect of sensors, the applications of PEDOT include a DNA sensor based on conducting PEDOT for direct detection that quantifies the targeted single strand DNA [21], and was served as a self-absorbing piezoelectric sensor consisting of conductive PEDOT [22]. Besides, an enzyme modified biosensor entrapped by PEDOT for the detection of phenolic compound [23] and an amperometric sensor coating of PEDOT for the measurement of chromate [24], were reported. Recently, Fabiano et al. [25] first reported the use of PEDOT to entrap glucose oxidase so that the detection of the glucose can be achieved successfully with a fast response time of $2-5 \mathrm{~s}$ and a good sensitivity of $15.2 \mathrm{~mA}$ $\mathrm{cm}^{-2} \mathrm{mM}^{-1}$. The sensor, however, suffered from the longterm instability in which the current decreases $50 \%$ at 17 days. A conjugated polymer PEDOT/PSS has been used as an electroactive hydrogel matrix in a biosensor or biomolecules-enhanced electrode with osmium as a mediator [26].

In this work, PEDOT was chosen as the matrix to entrap glucose oxidase (GOD) for preparing a glucose biosensor by controlling different electropolymerizing conditions in order to resolve the long-term instability issue. The stability of the glucose biosensor could relate to the sensing mechanism. In the presence of oxygen, the $\beta$-D-glucose (Glu) was reacted with GOD and oxidized to gluconolactone (GluAc) and hydrogen peroxide $\left(\mathrm{H}_{2} \mathrm{O}_{2}\right)$, and the reactions are expressed by Equations 1 and 2. Two protons and two electrons, transferred from the platinum substrate to the flavin moiety of the enzyme, were proposed [27].

$$
\begin{aligned}
& \mathrm{Glu}+\mathrm{Enz}_{\mathrm{ox}} \rightarrow \mathrm{GluAc}+\mathrm{Enz}_{\mathrm{red}} \\
& \mathrm{Enz}_{\mathrm{red}}+\mathrm{O}_{2} \rightarrow \mathrm{Enz}_{\mathrm{ox}}+\mathrm{H}_{2} \mathrm{O}_{2} \\
& \mathrm{H}_{2} \mathrm{O}_{2} \rightarrow \mathrm{O}_{2}+2 \mathrm{H}^{+}+2 \mathrm{e}^{-} \\
& E^{0}=0.60 \mathrm{~V} \text { vs. } \mathrm{Ag} / \mathrm{AgCl} / \text { sat'd } \mathrm{KCl}
\end{aligned}
$$

where $E n z_{\text {ox }}$ and $E n z_{\text {red }}$ represent the oxidized-state and the reduced-state of the enzyme, respectively. The reoxidized current of $\mathrm{H}_{2} \mathrm{O}_{2}$ is detected at the electrode (Eq. 3) in order to determine the glucose concentration; however, the produced $\mathrm{H}_{2} \mathrm{O}_{2}$ may destroy the PEDOT film. Moreover, it is a problem that the oxygen may not present and its concentration can not be fixed for all samples. Therefore, a mediator, such as ferricinium ions $\left(\mathrm{Fc}^{+}\right)$, was added in the sensing system to reduce the sensing potential and retard the production of $\mathrm{H}_{2} \mathrm{O}_{2}$. The alternative sensing reactions can be expressed as follows,

$$
\begin{aligned}
& \mathrm{Glu}+\mathrm{Enz}_{\mathrm{ox}} \rightarrow \mathrm{GluAc}+\mathrm{Enz}_{\mathrm{red}} \\
& \mathrm{Enz}_{\mathrm{red}}+2 \mathrm{Fc}^{+} \rightarrow \mathrm{Enz}_{\mathrm{ox}}+2 \mathrm{Fc} \\
& 2 \mathrm{Fc} \rightarrow 2 \mathrm{Fc}^{+}+2 \mathrm{e}^{-} \\
& E^{0}=0.13 \mathrm{~V} \text { vs. } \mathrm{Ag} / \mathrm{AgCl} / \text { sat'd } \mathrm{KCl}
\end{aligned}
$$

Following the reaction in Equation 1, two competitive reactions may occur, namely, the subsequent reaction may proceed according to Equation 2 in the presence of oxygen, or Equation 4 in the presence of ferricenium ions. Under a lower anodic potential, Equation 5 is driven to the right direction, while Equation 3 is not. According to Le Chatelier's principle, Equation 4 becomes dominant, comparing to Equation 2. That is, $\mathrm{Enz}_{\mathrm{red}}$ (the reduced-state of the enzyme) is being consumed primarily according to Equation 4, not Equation 2. Therefore, the addition of ferricenium ions retards Equation 2 in producing hydrogen peroxide. After the reaction of glucose and GOD, the reduced-state of the enzyme reacts with ferricinium ion to form the oxidized-state of the enzyme and ferrocene. The reoxidizing current of ferrocene to ferricinium ion was detected at the electrode surface at a low potential of $0.13 \mathrm{~V}$. The schematic illustration for glucose sensing is shown in Figure 1. Actually, there are two ways to transfer the electrons to the platinum electrode. One route is that Fc diffuses to the surface of the Pt electrode and gets oxidized, as shown in Figure 1. The other is that the electrons transfer to the Pt through the conducting polymer matrix. In the second case, Fc doesn't have to diffuse to the surface of the $\mathrm{Pt}$.

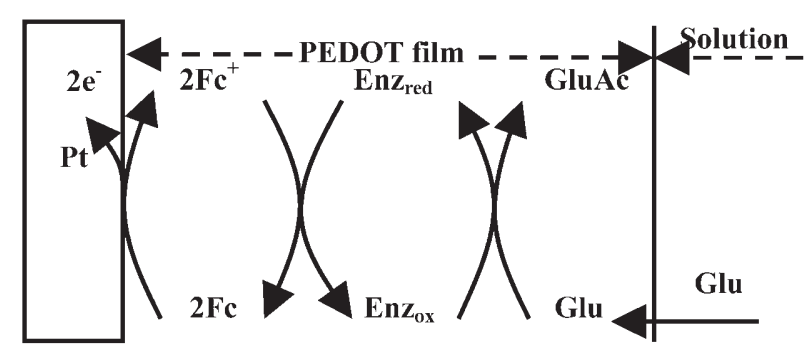

Fig. 1. Schematic illustration of sensing mechanism for electrocatalytic glucose on the PEDOT-modified platinum electrode surface, in which ferrocene serves as a mediator. 


\section{Experimental}

\subsection{Chemicals and Instruments}

Glucose oxidase (GOD) (EC 1, 1, 3, 4) type VII-S from Aspergillus niger, D- $(+)$-glucose, potassium chloride (99.0$100.5 \%$ ) and phosphate buffer saline (PBS, pH 7.4) were purchased from Sigma. The monomer, 3,4-ethylenedioxythiophene (EDOT), surfactant, polyethylene glycol (PEG, $\mathrm{MW}=20,000)$ and mediator, ferrocene $(98 \%)$ were purchased from Aldrich, Merck and Acros, respectively. Besides, deionized water (DIW) was used throughout the experiments. Before the measurement, the glucose solution was allowed to mutarotate over 24 hours for equilibrium of $\alpha$ - and $\beta$-anomers at room temperature. All electrochemical experiments, including $\mathrm{CV}$ and amperometric measurements were performed with a potentiostat/galvanostat (Autolab, model PGSTAT 30, Utrecht, the Netherlands).

\subsection{Preparation of the Enzyme Electrode}

A platinum disc electrode with a reactive area of $3.142 \mathrm{~mm}^{2}$ was polished by alumina powders $(0.05 \mu \mathrm{m}$ particle size $)$ and then washed by DIW. Afterward, the platinum disc electrode was polished by clean lint and rinsed by DIW again. Finally, the platinum electrode was ultrasonically cleaned in DIW for $5 \mathrm{~min}$. Subsequently, the enzyme electrode was prepared by incorporating the enzyme, GOD, into the electropolymerized PEDOT film on the Pt electrode in a three-electrode electrochemical system. An $\mathrm{Ag} / \mathrm{AgCl} / \mathrm{satu}$ rated $\mathrm{KCl}$ electrode and a platinum wire were acted as the reference electrode and the counter electrode, respectively. The deposition solution comprised of $10^{-2} \mathrm{MEDOT}, 10^{-3} \mathrm{M}$ PEG as surfactant and 1,000 unit glucose oxidase per milliliter in 0.02 M PBS. The role of PEG in the deposition solution not only enhances the EDOT solubility but also shows an excellent result in constructing a modified electrode [28]. In this study, two enzymatic electrodes $(\mathrm{PEDOT} / \mathrm{GOD} / \mathrm{Pt})$, which were controlled at different ranges of cycling potentials when electropolymerized by $\mathrm{CV}$ method, were prepared in order to investigate the effect of the formation of the microstructure on the PEDOT electrode. The potential of the first electrode was cycled between 0.2 and $1.2 \mathrm{~V}$ at a scan rate of $0.1 \mathrm{~V} / \mathrm{s}$ for 15 cycles (designated as electrode A) and the second electrode was cycled between 0.2 and $1.5 \mathrm{~V}$ (designated as electrode B). Subsequently, the prepared electrodes were both stored in $0.02 \mathrm{M}$ PBS at $4^{\circ} \mathrm{C}$ prior to use.

\subsection{Determination of the Sensing Potential}

The concentration of the glucose is detected at the PEDOTmodified electrode by an amperometric method in a threeelectrode electrochemical system. The working electrode, reference electrode, and counter electrode are PEDOTmodified enzyme electrode, $\mathrm{Ag} / \mathrm{AgCl} /$ saturated $\mathrm{KCl}$ elec- trode, and a platinum wire, respectively. The measurement of the glucose concentration was conducted in a $0.02 \mathrm{M} \mathrm{PBS}$ containing $0.3 \mathrm{mM}$ ferrocene as the mediator and $0.1 \mathrm{M} \mathrm{KCl}$ as the supporting electrolyte; beside, the electrolyte was stirred in the open air with a magnetic stirrer at $100 \mathrm{rpm}$. In order to determine the suitable sensing potential, different potentials were applied between 0.1 and $1.0 \mathrm{~V}$ to find the limiting current plateau. In other words, when the background current reached a steady-state value in each applied potential, a $0.1 \mathrm{M}$ glucose was added to raise the glucose concentration in the electrolyte solution to be up to $5 \mathrm{mM}$ and collect the new steady-state current. Therefore, the net sensing current is plotted as a function of the applied potential and suitable operating potentials in the range of limiting current plateau are obtained.

\subsection{The Sensing Performance of the PEDOT-Modified Glucose Biosensor}

The PEDOT-modified electrode was used to determine a calibration curve of the glucose concentration by applying a suitable potential of $0.35 \mathrm{~V}$, which is in the limiting current plateau region. A three-electrode electrochemical system, which contains an electrolyte of $0.02 \mathrm{M}$ PBS, $0.3 \mathrm{mM}$ ferrocene and $0.1 \mathrm{M} \mathrm{KCl}$, was employed. The current data were collected by injecting $0.1 \mathrm{M}$ glucose solution continuously with a sampling time of $60 \mathrm{~s}$, allowing the current response to achieve new steady-state one, where a current disturbance is less than $\pm 20 \mathrm{nA}$. Thus, from the steady-state amperometric responses of the PEDOT/GOD/Pt biosensor, the relationship between the concentration of the glucose and its corresponding reactive current can be established. Additionally, the interference materials such as ascorbic acid (AA), $8 \times 10^{-5} \mathrm{M}$, and uric acid (UA), $4 \times 10^{-4} \mathrm{M}$, were added into the glucose solution in separate experiments to measure the interference, and the long-term stability of the biosensor was tested each day over a period of 18 days.

\section{Results and Discussion}

\subsection{CVs of the Enzyme Electrode}

The CVs of the PEDOT conducting polymer to entrap the glucose oxidase on the bare platinum electrode, respectively, for electrode $\mathrm{A}$ and $\mathrm{B}$, which were made in different potential ranges, are shown in Figure $2 \mathrm{a}$ and $\mathrm{b}$. Electrode $\mathrm{A}$ was scanned between 0.2 and $1.2 \mathrm{~V}$, while that of electrode $\mathrm{B}$ between 0.2 and $1.5 \mathrm{~V}$. It is clearly seen from Figure $2 \mathrm{a}$ (electrode A) that the reaction current increases sharply when the applied potential is larger than $0.7 \mathrm{~V}$, which reveals the formation of the radical cations [29]. After second cycle, the oxidation and reduction currents increase with the continuous scanning between the potential ranges of 0.2 and $0.8 \mathrm{~V}$. The increased current implies that the EDOT radical cations start to electropolymerize onto the platinum electrode. The oxidation current, however, decreases when the 

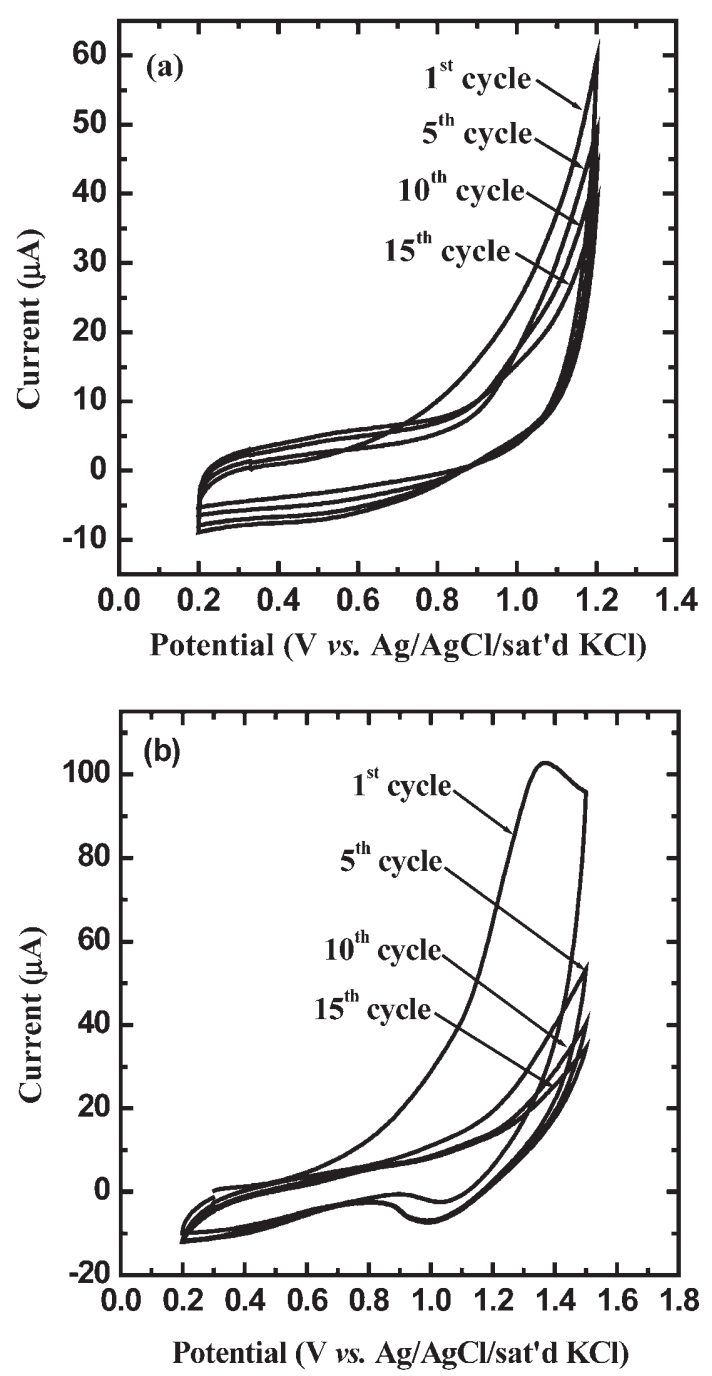

Fig. 2. The cyclic voltammograms of electropolymerized PEDOT film at a scan rate of $0.1 \mathrm{~V} / \mathrm{s}$ for a) electrode A $(0.2-1.2 \mathrm{~V})$ and b) electrode B $(0.2-1.5 \mathrm{~V})$.

sweeping potential is over $1.0 \mathrm{~V}$. It is inferred that the high potential range may result in the decomposition of water in the electrolyte and cause the partial degradation of the PEDOT film.

For comparison with electrode A, the cyclic voltammograms of electrode $\mathrm{B}$, which is scanned between 0.2 and $1.5 \mathrm{~V}$, are shown in Figure 2b. Although the high applied oxidative side potential cause the high-current response at the first cycle, the degradation on the electrode B is more serious than that of the electrode $\mathrm{A}$, as evidenced from the unobvious characteristics of the PEDOT between 0.2 and $0.8 \mathrm{~V}$ and the subsequent rapid decreased current response. Because the PEDOT is served as the matrix to the entrap enzyme and is electroactive, the decreased current implies the loss of the electroactivity and the hindrance of the polymer formation; thus it is important to stabilize the PEDOT matrix. By changing the deposition parameters, especially in the oxidation side, and the sensing mediator, the long-term instability of the enzyme electrode can be improved. In the following sections, the analytic results, the sensitivity, limit of detection, calibration curve and interference of the electrode A and electrode B will be compared and discussed.

\subsection{Limiting Current Plateau}

The as-deposited PEDOT-modified enzyme electrode (electrode A) was used to measure current-time response curves ( $i-t$ curve) before and after injecting a $5 \mathrm{mM}$ glucose solution into the electrolyte at different applied potentials ranged from 0.1 to $1.0 \mathrm{~V}$. At each applied potential, after a steady-state background current is reached, the current rises sharply and reaches a new steady-state value when adding $5 \mathrm{mM}$ glucose solution. This means that the increased current is contributed from the reaction of glucose, and each reaction step can be described in Figure 1. When the glucose molecules diffuse into the PEDOT matrix, it reacts with the oxidized form of the enzyme, and then the electron exchange occurs between the reduced form of the enzyme and $\mathrm{Fc}$ ions. Then the reoxidation current of $\mathrm{Fc}$ is detected on the Pt electrode surface. The measured results show that the prepared PEDOT-modified enzyme electrode could entrap glucose oxidase successfully to sense glucose. After the chronoamperometric experiments ( $i-t$ curve) were repeated from low potentials to high potentials, a steadystate current-potential curve $(i-E$ curve) was obtained and plotted in Figure 3. In Figure 3, it is clear that the PBS background current, which was contributed from the conducting polymer in PBS, increases slowly as the applied potential increases. From the net current curve, two plateaus can be observed; one occurs between $0.23-0.40 \mathrm{~V}$ and the other locates between $0.50-0.70 \mathrm{~V}$. The reaction current on the first plateau $(0.23-0.40 \mathrm{~V})$ was contributed from the reoxidation of the Fc molecules on the Pt electrode surface (Eq. 5), which was generated by the electron transfer between the $\mathrm{Enz}_{\mathrm{red}}$ and $\mathrm{Fc}^{+}$(Eq. 4). On the other hand,

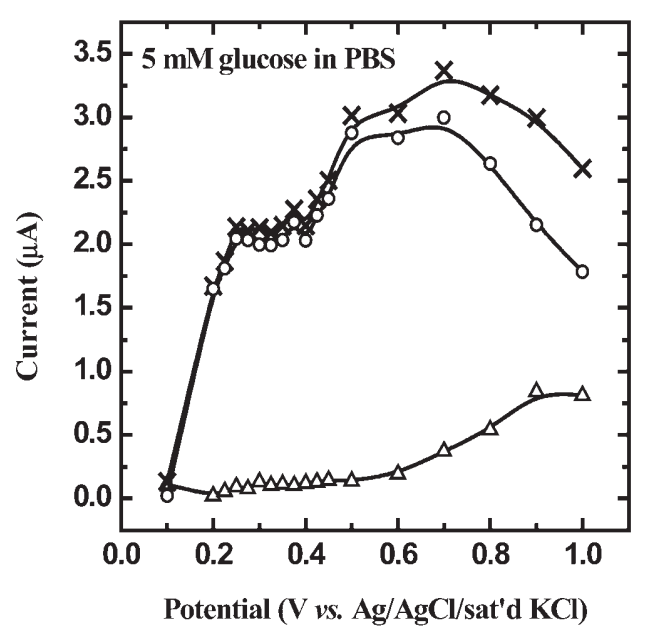

Fig. 3. The $I-E$ curve of sensing $5 \mathrm{mM}$ glucose in PBS for electrode A. $\triangle$ ) The background current of PBS, $\times$ ) the total reaction current, $\bigcirc$ ) the net current. 
the current on the second plateau $(0.50-0.70 \mathrm{~V})$ was resulted from the reoxidation of the hydrogen peroxide, which was produced from the $E n z_{\text {red }}$ and the dissolved oxygen in electrolytes. The subsequent reaction can be described by Equations 1, 2 and 3. In addition to the two plateaus, when the applied potential was larger than $0.70 \mathrm{~V}$, the net current decreases gradually. The decreased current may result from the electroactivity loss of the PEDOT film under high applied potentials [30-31]. Thus, in order to avoid the damage of the conducting polymer film and reduce the inference of the side-reaction, the sensing potential was chosen properly in the range of the first potential plateau. So a potential of $0.35 \mathrm{~V}$ was chosen as the working potential for detection of the glucose concentration to obtain the calibration curve in the following experiment.

\subsection{The Calibration Curve of the Glucose and the Characteristics of the Biosensor}

The total current as a function of the increased glucose concentration, between 0.1 and $30 \mathrm{mM}$, with a sampling time of $60 \mathrm{~s}$ at each concentration level, was measured and shown in Figure 4 . The defined response time, when the sensing current reached $95 \%$ of the steady-state current (disturbance $\leq 20 \mathrm{nA}$ ), was calculated to be about $4-10 \mathrm{~s}$ from Figure 4 at each added glucose concentration. This reveals that the sensing system can provide a rapid response for analysis at different concentration of glucose. The same experiments were repeated for four times, and the relationship between the reacted current and the glucose concentration $(i-C$ curve) are plotted in Figure 5a. The figure shows the average reacted current values and the upper and lower values; besides, the linear range of the $i-C$ response is replotted in Figure 5b. In Figure 5a, although electrode A and electrode $\mathrm{B}$ both present a linear relationship between net current and glucose concentration on the range of lower glucose concentration (up to $10 \mathrm{mM}$ ), electrode A exhibits a better sensing performance than that of electrode B both in sensitivity and the reproducibility. From the results, it is deduced that the deposited potential range of the enzyme electrode plays an important role on the sensing results. As discussed before, the electrode B may encounter serious side-reactions to cause the damage to the microstructure of the PEDOT at the scanning potential of $1.5 \mathrm{~V}$ during electropolymerization. Moreover, the sensing current of electrode B is smaller than that of electrode A and this may result from the fewer entrapped amounts of enzymes inside the destructive PEDOT film.

From Figure 5a, the linear ranges of the enzyme electrodes, for both electrode A and electrode B, lies between 0.1 $10.0 \mathrm{mM}$. When the results were re-plotted in Figure $5 \mathrm{~b}$, the average sensitivity of the electrode $A$ and $B$ were calculated as 12.42 and $9.05 \mathrm{~mA} \mathrm{~cm}^{-2} \mathrm{M}^{-1}$, respectively. Besides, the limit of detection $(L O D)$ of the enzyme electrodes is expressed in Equation 6, which is defined by the International Union of Pure and Applied Chemistry (IUPAC).

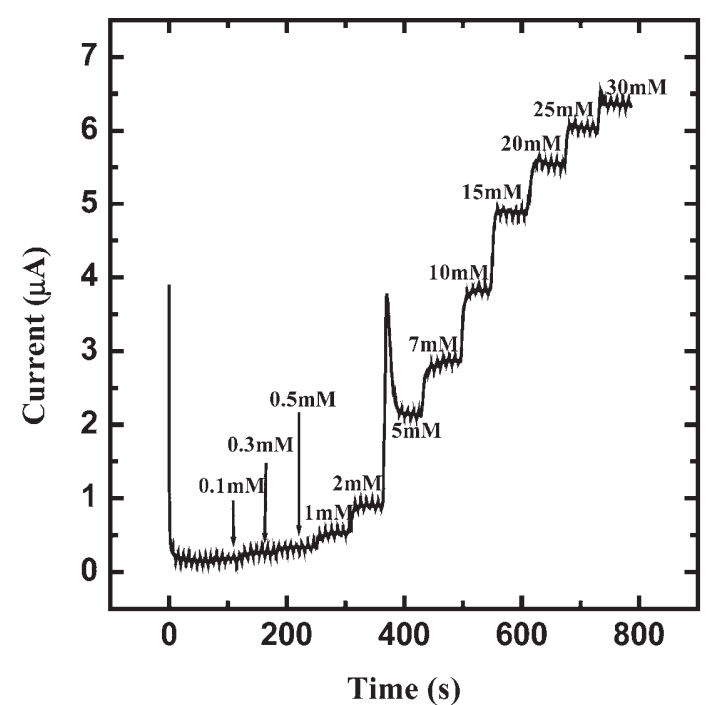

Fig. 4. The responses of electrode A with different glucose concentrations in PBS. The sensing potential is $0.35 \mathrm{~V}$ vs. Ag/ $\mathrm{AgCl} /$ saturated $\mathrm{KCl}$ and the electrolyte contains $0.02 \mathrm{M}$ PBS and $0.1 \mathrm{M} \mathrm{KCl}$.

$L O D=k S D / S E N$

where $k$ is a constant, $S E N$ is sensitivity and $S D$ is the standard deviation of the background signal of PBS in the system. Based on $99.7 \%$ confidence interval $(k=3)$, the $L O D$ for electrode $\mathrm{A}$ and electrode $\mathrm{B}$ are $0.13 \mathrm{mM}$ and $0.05 \mathrm{mM}$, respectively.

Comparing to the results of glucose sensing reported in the literatures (Table 1), the results of No. 7-10 can provide a rapid sensing response and a good sensitivity, and can be used for detecting blood glucose range of human, when using PEDOT as the matrix. Although the linear ranges reported in literatures $[5,9,17,32]$ (No. $1-4$ in Table 1) also locate in the range of human blood, but their response times are not as fast as the glucose biosensors entrapped by PEDOT (No. 7-10). On the other hand, the response times for No. 5 [33] and 6 [34] are very fast, but the linear sensing ranges are not acceptable for sensing the blood glucose in human body. As a result, it is shown that the PEDOTmodified electrode A has good sensing performance on glucose. The linear range, sensitivity, and response time of electrode A in this work are similar to those of the results reported in the literature (No. 7 [25]), but more important is that electrode A exhibits a better long-term stability when comparing to the literature [25]. The results of long-term operation will be discussed in another subsection below.

\subsection{Enzyme Kinetics}

By using glucose oxidase to sense the glucose, the reaction should obey Michaelis-Menten mechanism and provide two kinetic constants, Michaelis constant $\left(K_{\mathrm{m}}\right)$ and maximum rate $\left(v_{\max }\right)$. According to the pseudosteady state assumption (PSSA), the mechanism expressed in Equation 7 can be 

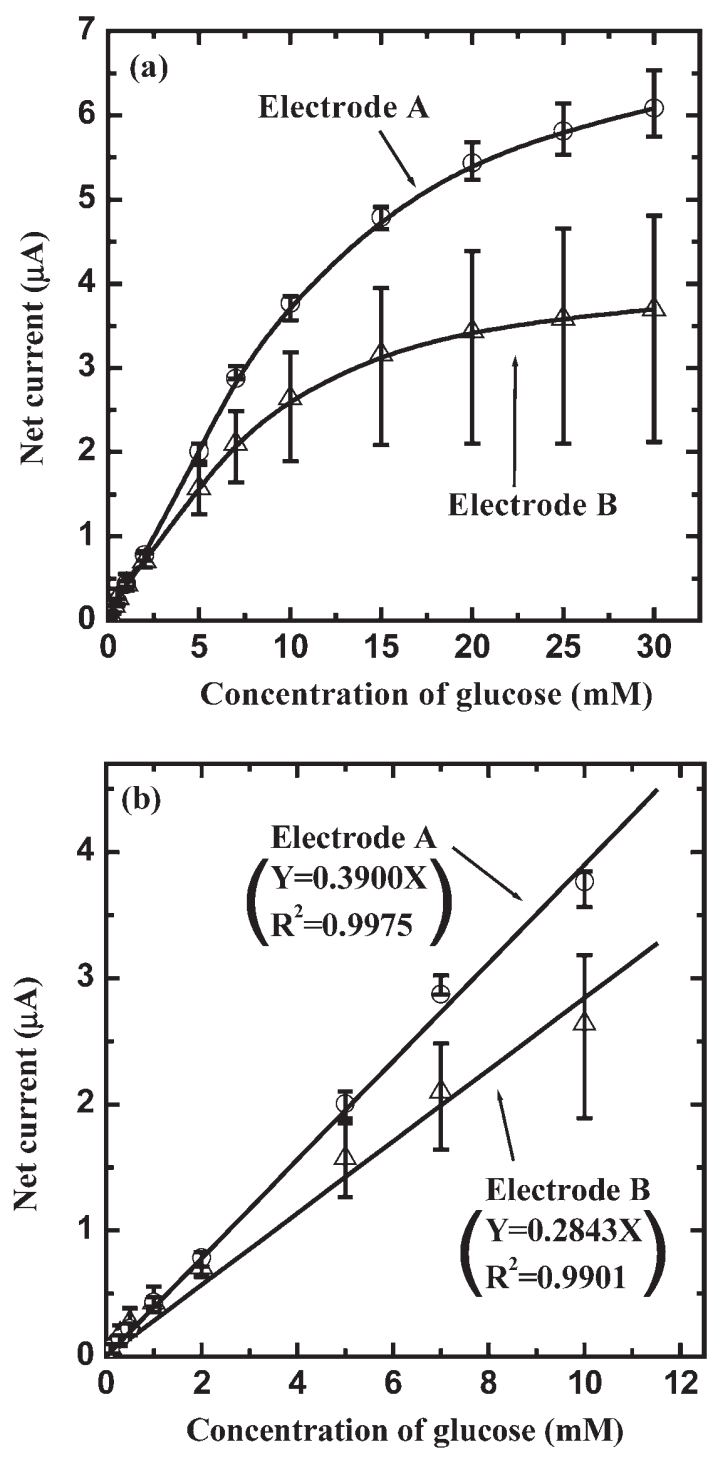

Fig. 5. The calibration curves of the PEDOT-modified glucose sensors at $0.35 \mathrm{~V}$ vs. $\mathrm{Ag} / \mathrm{AgCl} /$ saturated $\mathrm{KCl}$; O) electrode $\mathrm{A}$ and $\triangle$ ) electrode B. a) The data are adopted by four times experiments and $b$ ) the linear regression of the dynamic range $(0.1-10.0 \mathrm{mM})$.

described by Michaelis - Menten equation, shown in Equation 8 .
$\mathrm{S}+\mathrm{E} \underset{k_{-1}}{\stackrel{k_{+1}}{\rightleftarrows}} \mathrm{ES} \stackrel{k_{2}}{\longrightarrow} \mathrm{E}+\mathrm{P}$

$v=v_{\max }[\mathrm{S}] /\left(K_{\mathrm{m}}+[\mathrm{S}]\right)$

where S, E and P represent substrate, enzyme and product, respectively. In this system, $\mathrm{S}, \mathrm{E}$ and $\mathrm{P}$ are glucose, glucose oxidase and Fc, respectively. According to Equation 8, a regression curve for the data (electrode $\mathrm{A}$ ) in Figure $5 \mathrm{a}$ is shown in Figure 6, and two Michaelis-Menten constants are obtained; $K_{\mathrm{m}}=17.27 \mathrm{mM}$ and $v_{\max }\left(\right.$ or $\left.I_{\max }\right)=9.88 \mu \mathrm{A}$. The value of $K_{\mathrm{m}}$ is reasonable, when compared with the value of $K_{\mathrm{m}}$ reported previously $\left(K_{\mathrm{m}}=16.4 \mathrm{mM}\right)$ when a glucose biosensor entrapped an enzyme with poly $(o$-aminophenol) [34]. Figure 6 shows a good enzymatic behavior for amperometric detection of glucose by using the conducting PEDOT. The linear current response lies between 0.1 and $10.0 \mathrm{mM}$, which is in the range of human blood (4.0$8.0 \mathrm{mM})$.

\subsection{Interference and Stability of the Glucose Biosensor}

If the applied potential is high enough to oxidize other electroactive reactants in the sensing solution, the reacted net current would contain the interference signal, thus the real concentration of the substrate would be overestimated. The common interferences of AA and UA in the blood of human beings have normal concentration ranges of 34$79 \mu \mathrm{M}$ and $0.18-0.42 \mathrm{mM}$, respectively. In order to reduce the effect of the interference on the working electrode's surface, one effective method is to lower the sensing potential. Therefore, the ferrocene added in this system can successfully diffuse inside into the PEDOT matrix and decrease the sensing potential for the reoxidization of ferrocene (Eq. 5).

In this subsection, the interference effect on the electrode $\mathrm{A}$ in two different systems is compared. One was applied a potential of $0.35 \mathrm{~V}$ in a buffer solution containing $\mathrm{Fc}^{+}$, and the other was applied a potential of $0.65 \mathrm{~V}$ in a buffer solution with no additional species added. The results are shown in Figure 7; when comparing to the sensing current of

Table 1. The performances of glucose biosensors reported in the literatures.

\begin{tabular}{lllllllll}
\hline No. & References & Method & Matrix & Base & $\begin{array}{l}\text { Linear range } \\
(\mathrm{mM})\end{array}$ & $\begin{array}{l}\text { Sensitivity } \\
\left(\mathrm{mA} \mathrm{cm} \mathrm{m}^{-1}\right)\end{array}$ & $\begin{array}{l}\text { Response time } \\
(\mathrm{s})\end{array}$ & $\begin{array}{l}\text { Stability } \\
(\text { days })\end{array}$ \\
\hline 1 & {$[9]$} & Entrapment & PPy [a] & $\mathrm{Pt}$ & $1.0-10.0$ & - & $20-40$ & $20(70 \%)$ \\
2 & {$[17]$} & Entrapment & PANI [b] & $\mathrm{Pt}$ & $0.01-12.0$ & 13.6 & 30 & - \\
3 & {$[5]$} & Covalent & 1,1-DMFc & $\mathrm{C}$ & $1.0-30.0$ & 6.63 & $60-90$ & - \\
4 & {$[32]$} & Covalent & Copolymer & $\mathrm{Pt}$ & $0.0-15.0$ & - & 20 & - \\
5 & {$[33]$} & Entrapment & Poly-PPD [c] & $\mathrm{Pt}$ & $0.05-3.0$ & - & $>2$ & $30(70 \%)$ \\
6 & {$[34]$} & Entrapment & Poly-OAP [d] & $\mathrm{PGCE}$ & $0.001-1.0$ & - & 3 & $30(70 \%)$ \\
7 & {$[25]$} & Entrapment & PEDOT & $\mathrm{Pt}$ & $0.2-8.0$ & 15.2 & $2-5$ & $10(70 \%)$ \\
8 & {$[28]$} & Entrapment & PEDOT & $\mathrm{Pt}$ & $0.0-22.0$ & 3.0 & - & -10 \\
9 & Electrode A & Entrapment & PEDOT & $\mathrm{Pt}$ & $0.1-10.0$ & 12.42 & $4-10$ & $>18(80 \%)$ \\
10 & Electrode B & Entrapment & PEDOT & $\mathrm{Pt}$ & $0.1-10.0$ & 9.05 & $4-10$ & - \\
\hline
\end{tabular}

[a] PPy: polypyrrole; [b] PANI: Polyaniline; [c] Poly-PPD: Poly(p-phenylenediamine); [d] Poly-OAP: Poly(o-aminophenol) 


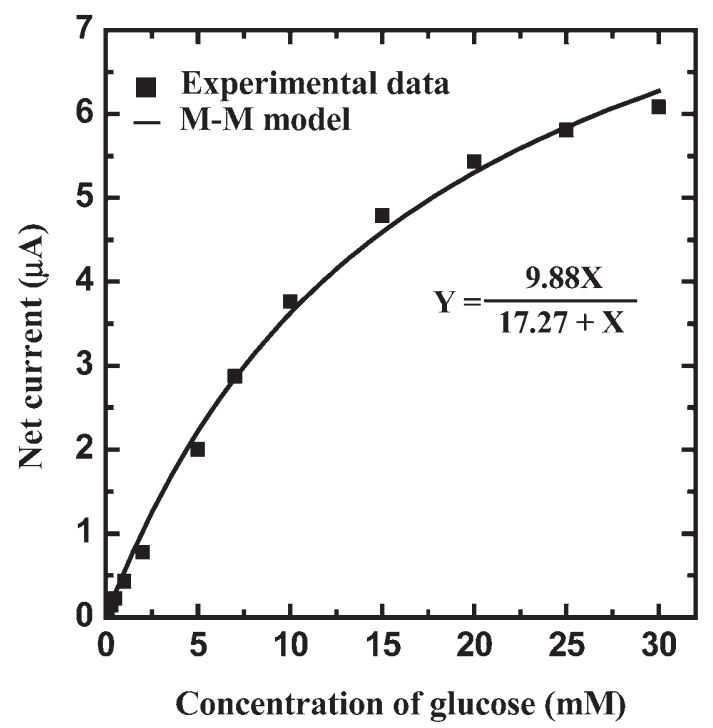

Fig. 6. The regression of the sensing experimental data of electrode A by Michaelis-Menten model.

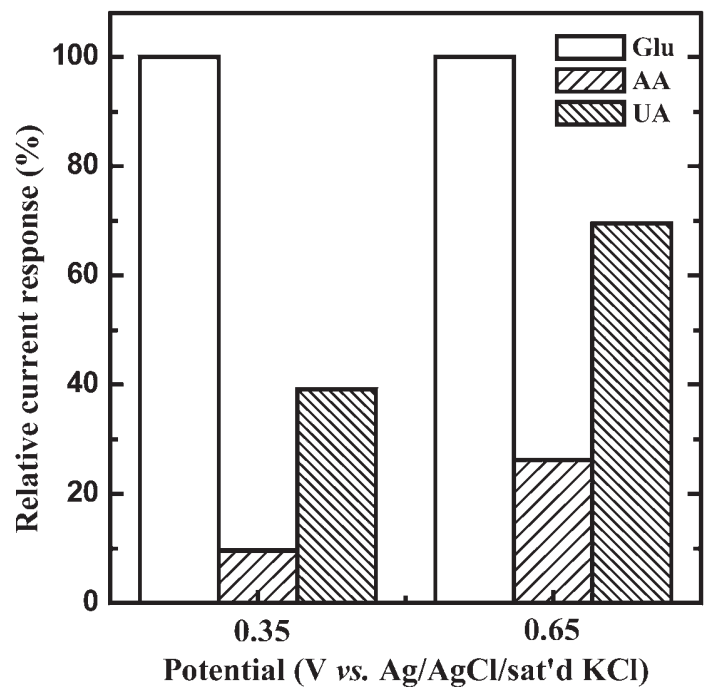

Fig. 7. The sensing selectivities of the enzyme electrode $\mathrm{A}$ at $0.35 \mathrm{~V}$ and $0.65 \mathrm{~V}$ vs. $\mathrm{Ag} / \mathrm{AgCl} /$ saturated $\mathrm{KCl}$. The absolute responses are defined as the percentage of the reaction current of AA and UA comparing to that of glucose in $0.02 \mathrm{M}$ PBS.

glucose $(100 \%)$, AA and UA increase $9.7 \%$ and $39.1 \%$ in current at $0.35 \mathrm{~V}$ and $26.3 \%$ and $69.5 \%$ in current at $0.65 \mathrm{~V}$, respectively. The results imply that the system with Fc added as the mediator can reduce the sensing potential for the reoxidation of $\mathrm{Fc}$ (Eq. 5), instead of sensing at a higher oxidation potential for $\mathrm{H}_{2} \mathrm{O}_{2}$ (Eq. 3). This means that a lower potential $(0.35 \mathrm{~V})$ reduces the interferences of $\mathrm{AA}$ and UA on the glucose sensing, as compared to those at a higher applied potential $(0.65 \mathrm{~V})$.

In long-term operation, it is important to retain the sensitivity for a good glucose biosensor. The operating stability of the electrode A, which sensed the reoxidized current of ferrocene at $0.35 \mathrm{~V}$ for one time each day, is

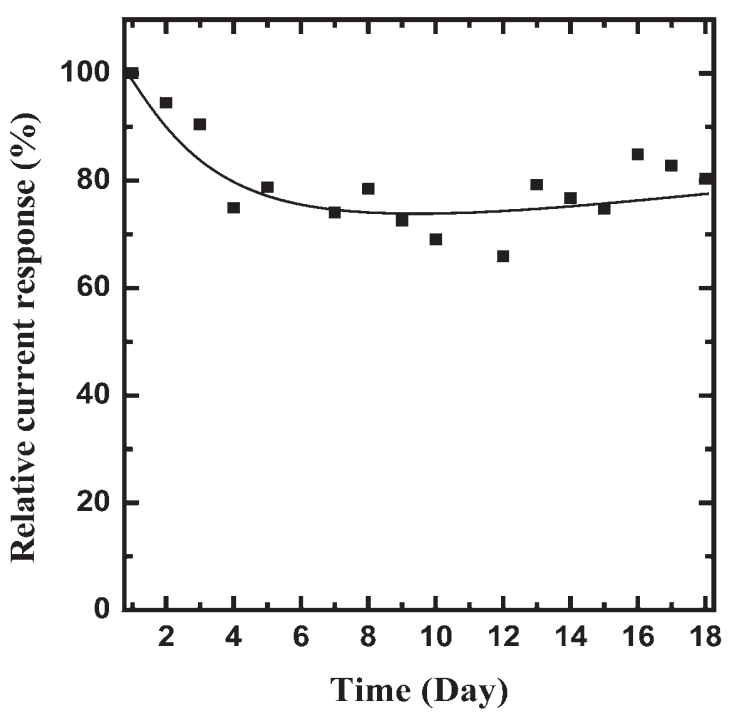

Fig. 8. The long-term stability of the PEDOT-modified glucose biosensor (electrode $\mathrm{A}$ ) at a sensing potential of $0.35 \mathrm{~V}$ vs. $\mathrm{Ag} /$ $\mathrm{AgCl} / \mathrm{saturated} \mathrm{KCl}$.

shown in Figure 8. From the result, it is found that the sensing current still retains about $80 \%$ of its original value for at least 18 days and hence it is concluded that the adding of ferrocene not only lower the sensing potential but also mitigates the electroactivity loss of conducting polymer in a long-term operation, avoiding the low enzyme entrapment caused by the degraded polymer chains at a higher potential. In another aspect, the electrode with an upper deposition potential controlled at $1.2 \mathrm{~V}$ was more stable than that of the electrode set at $1.5 \mathrm{~V}$. The reason has to do with the decomposition of water at higher potentials as discussed in section 3.1. Thus, the electrode A could improve the longterm instability as seen in literature [25], in which the sensitivity decreases $30 \%$ at 10 days and $50 \%$ at 17 days.

\section{Conclusions}

In this work, it was confirmed that the conducting polymer, PEDOT, can successfully entrap glucose oxidase so as to construct a glucose biosensor. Different sensing mechanisms, as seen at different applied potentials, are also proposed. In proposing the PEDOT matrix, it was not advantageous to entrap enzyme by depositing at a higher potential. The enzyme electrode prepared at a higher potential resulted in a serious destruction of PEDOT matrix and caused a lower sensitivity and reproducibility of the biosensor. When ferrocene is added as the mediator, it not only reduces the working potential to $0.35 \mathrm{~V}$ but also improves the instability of PEDOT operating at higher potentials. The linear sensing range, sensitivity, limit of detection and response time are $0.1-10.0 \mathrm{mM}, 12.42 \mathrm{~mA}$ $\mathrm{cm}^{-2} \mathrm{M}^{-1}, 0.13 \mathrm{mM}$ and $4-10 \mathrm{~s}$, respectively. The current signal of the interference contributed $9.7 \%$ and $39.1 \%$ for the $\mathrm{AA}$ and UA, respectively, at $0.35 \mathrm{~V}$. In long-term 
stability test, the current still retains ca. $80 \%$ of its original one for at least 18 days. In addition to sensing glucose, the immobilization technique of PEDOT can also be useful for other substrates, providing a wide application in different kinds of microbiosensors.

\section{Acknowledgements}

This work was supported by the Program for Promoting Academic Excellence of University, sponsored by the Ministry of Education of the Republic of China, under grant no. EX91-E-F-FA09-5-4. P.-C. Nien would like to acknowledge a Summer Research Fellowship, awarded by the National Research Council of the Republic of China, under grant no. NSC93-2815-C-002-039-E.

\section{References}

[1] L. C. Jr. Clark, C. Lyons, Ann. NY Acad. Sci. 1962, 102, 29.

[2] A. J. Cunningham, Introduction to Bioanalytical Sensors, Wiley, New York 1998, pp. 167-192.

[3] Z. Zhujun, W. R. Seitz, Anal. Chem. 1986, 58, 220.

[4] S. Gamati, J. H. T. Luong, A. Mulchandani, Biosens. Bioelectron. 1991, 6, 125.

[5] A. E. G. cass, G. Davis, G. D. Francis, H. A. O. Hill, Anal. Chem. 1984, 56, 667.

[6] J. Parellada, A. Narvaez, E. Dominguez, I. Katakis, Biosens. Bioelectron. 1997, 12, 267.

[7] S. M. Reddy, P. Vadgama, Anal. Chim. Acta 2002, 461, 57.

[8] S. Cosnier, Biosens. Bioelectron. 1999, 14, 443.

[9] N. C. Foulds, C. R. Lowe, J. Chem. Soc. Faraday Trans. 1 1986, 82, 1259.

[10] P. N. Bartlett, J. M. Cooper, J. Electroanal. Chem. 1993, 362, 1.
[11] M. Trojanowicz, O. Geschke, T. Krawczyk, K. Cammann, Sens. Actuators B Chem. 1995, 28, 191.

[12] S. L. Mu, H. G. Xue, Sens. Actuators B Chem. 1996, 31, 155.

[13] M. Hiller, c. Kranz, J. Huber, P. Bauerle, W. Schuhmann, Adv. Mater. 1996, 8, 219

[14] G. Fortier, E. Brassard, D. Belanger, Biosens. Bioelectron. 1990, 5, 473.

[15] S. Cosnier, Biosens. Bioelectron. 1999, 14, 443.

[16] S. Cosnier, A. Lepellec, Electochim. Acta 1999, 44, 1833.

[17] H. Yamato, M. Ohwa, W. Wernet, J. Electroanal. Chem. 1995, 397, 163.

[18] K. Lerch, F. Jonas, M. Linke, J. Chim. Phys. 1998, 95, 1506.

[19] A. Kros, N. A. J. M. Sommerdijk, R. J. M. Nolte, Sens. Actuators B Chem. 2005, 106, 289.

[20] L. Groenendaal, F. Jonas, D. Freitag, H. Pielartzik, J. R. Reynolds, Adv. Mater. 2000, 12, 481.

[21] K. Krishnamoorthy, R. S. Gokhale, A. Q. Contractor, A. Kumar, Chem. Commun. 2004, 7, 820.

[22] D. Setiadi, Z. He, J. Hajto, T. D. Binnie, Infrared Phys. 1999, 40, 267.

[23] C. Vedrine, S. Fabiano, C. Tran-Minh, Talanta 2003, 59, 535.

[24] C. Michel, F. Battaglia-Brunet, C. T. Minh, M. Bruschi, I. Ignatiadis, Biosens. Bioelectron. 2003, 19, 345.

[25] S. Fabiano, C. Tran-Minh, B. Piro, L. A. Dang, M. C. Pham, O. Vittori, Mat. Sci. Eng. C-Bio. S. 2002, 21, 61.

[26] P. Asberg, O. Inganas, Biosens. Bioelectron. 2003, 19, 199.

[27] A. Haouz, C. Twist, C. Zentz, P. Tauc, B. Alpert, Eur. Biophys. J. 1998, 27, 19.

[28] B. Piro, L. A. Dang, M. C. Pham, s. Fabiano, C. Tran-Minh, J. Electroanal. Chem. 2001, 512, 101.

[29] J. Roncali, Chem. Rev. 1992, 92, 711.

[30] M. Dietrich, J. Heinze, G. Heywang, F. Jonas, J. Electroanal. Chem. 1994, 369, 87.

[31] G. Zotti, S. Zecchin, G. Schiavon, Chem. Mater. 2000, 12, 2996.

[32] A. Kros, R. J. M. Nico, N. A. J. M. Sommerdijk, J. Polym. Sci. Pol. Chem. 2002, 40, 738.

[33] J.-J. Xu, H.-Y. Chen, Anal. Biochem. 1999, 280, 221.

[34] Z. Zhang, H. Liu, J. Deng, Anal. Chem. 1996, 68, 1632. 